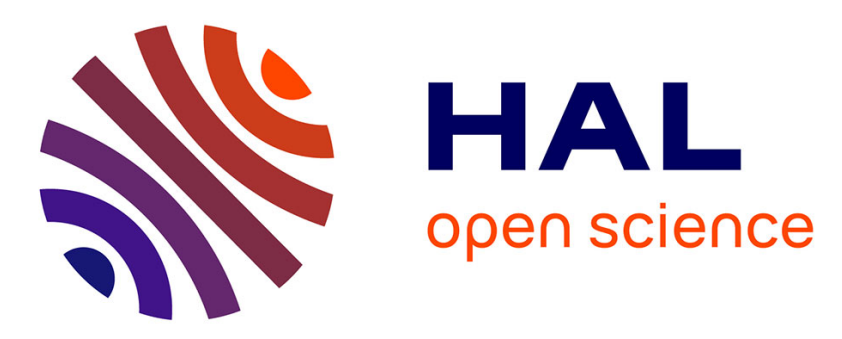

\title{
Mechanical characterization of aortic valve tissues using an inverse analysis approach
}

Colin Laville, Víctor Andrès Acosta-Santamaría, Olfa Trabelsi, Stéphane Avril, Yannick Tillier

\section{- To cite this version:}

Colin Laville, Víctor Andrès Acosta-Santamaría, Olfa Trabelsi, Stéphane Avril, Yannick Tillier. Mechanical characterization of aortic valve tissues using an inverse analysis approach. Computer Methods in Biomechanics and Biomedical Engineering, 2015, Special Issue: French Society of Biomechanics 18 (1), pp.1976-1977. 10.1080/10255842.2015.1070586 . hal-01275964

\section{HAL Id: hal-01275964 \\ https://hal.science/hal-01275964}

Submitted on 19 Feb 2016

HAL is a multi-disciplinary open access archive for the deposit and dissemination of scientific research documents, whether they are published or not. The documents may come from teaching and research institutions in France or abroad, or from public or private research centers.
L'archive ouverte pluridisciplinaire HAL, est destinée au dépôt et à la diffusion de documents scientifiques de niveau recherche, publiés ou non, émanant des établissements d'enseignement et de recherche français ou étrangers, des laboratoires publics ou privés. 


\title{
Mechanical characterization of aortic valve tissues using an inverse analysis approach
}

\author{
C. Laville ${ }^{\mathrm{a} *}$, V. Acosta-Santamaria ${ }^{\mathrm{b}}$, O. Trabelsi ${ }^{\mathrm{b}}, \mathrm{S}$. Avril $^{\mathrm{b}}$, and Y. Tillier ${ }^{\mathrm{a}}$ \\ ${ }^{a}$ MINES ParisTech, CEMEF - Centre de Mise en Forme des Matériaux, CNRS UMR 7635, Sophia Antipolis, France; \\ ${ }^{b}$ Ecole Nationale Supérieure des Mines, CIS-EMSE, CNRS UMR 5307, Saint-Etienne, France
}

Keywords: inverse analysis; finite element; hyperelasticity; transversaly isotropic, aortic valve

\section{Introduction}

The use of numerical simulation to investigate heart and valvular mechanics is becoming increasingly popular. In particular, finite element analysis is often used to support the operation planning procedure as well as the design of new prostheses with mechanical properties as close as possible to those of natural tissues and an even better biocompatibility. With one of the highest prevalence of cardiovascular degenerative diseases [1], aortic valves (AV) have been widely studied during the last decades.

The elastic [2] and time-dependent [3] behaviors of the $\mathrm{AV}$ leaflets under physiological biaxial loading states have been previously investigated in the literature over a wide range of loading conditions.. As most soft tissues, AV has an oriented network of collagen fibers embedded in an elastin matrix, which is responsible for their hyperelastic and anisotropic behaviors. Accordingly, non-linear transverse isotropic constitutive equations are often used assuming a macroscopicallyidentifiable preferred fiber direction.

In this study a new method is proposed in order to estimate relevant material and structural properties of $\mathrm{AV}$ while reducing at the same time the number of complex and time-consuming experiments. An inverse analysis procedure based on the finite element computation of planar biaxial tensile tests was used to set-up a reduced protocol. This protocol was then experimentally reproduced to identify real material parameters. The obtained material parameters will be later used to model heart valve tissues.

\section{Methods}

\subsection{Sensitivity analysis using numerical simulation}

In order to model the AV tissue behavior, the HGO [4] and a modified $\mathrm{HGO}$ material models were implemented in the finite element code FORGE® (based on an updated Lagrangian formulation). Both models are transversely isotropic and hyperelastic, with a local fiber direction defined per element. Constitutive equation parameters were set arbitrarily. A generic biaxial tensile test was modeled by applying different loading conditions (different stretch ratios in the two principal orthogonal directions) to a $15 \times 12 \mathrm{~mm}^{2}$ rectangular specimen with an homogenous thickness of $0.2 \mathrm{~mm}$. The specimen was meshed using linear tetrahedron minielements. A set of curves was obtained for each loading condition. A sensitivity analysis followed. It consisted in determining an optimal number of experimental conditions, i.e. by removing unnecessary experiments, that enabled us to accurately identify the set of parameters used for creating the reference curves.

\subsection{Experimental data}

Fresh native AV valves collected from porcine hearts were stored in an isotonic saline solution at $4^{\circ} \mathrm{C}$ less than 48 hours. Rectangular samples were carefully excised from the center of the leaflets and five thickness measurements were made and averaged for the thickness of each specimen. The specimen widths ranged from 15 $\mathrm{mm}$ to $10 \mathrm{~mm}$ depending on the valve annular diameter. Samples were mounted on a biaxial testing device (Bose ${ }^{\circledR}$ planar biaxial TestBench instrument) with four hooks on each side. The assumed samples preferred fiber direction (supposed to be along the circumferential direction of the valve) was aligned with the first tensile axis. The specimens were tested at room temperature.

Samples were subjected to small pre-stress and preconditioned during ten triangular cycles before applying each loading condition. In order to characterize the mechanical properties, we only applied the boundary conditions given by the previous sensitivity analysis, with a maximum membrane tension of $40 \mathrm{~N} / \mathrm{m}$.

\subsection{Parameter identification}

Inverse analysis identification was carried out using a

*Corresponding author. Email: colin.laville@mines-paristech.fr 
metamodel-assisted evolutionary algorithm. The set of material parameters was obtained thanks to the force $v s$. displacement curves obtained experimentally and to the computed results obtained with the finite element model of the biaxial tensile tests, under similar conditions.

\section{Results and discussion}

\subsection{Results}

Material models were validated against published data. The rheological parameter sensitivity analysis based on different loading conditions led to a minimum number of experimental protocols to be performed (Figure 1).
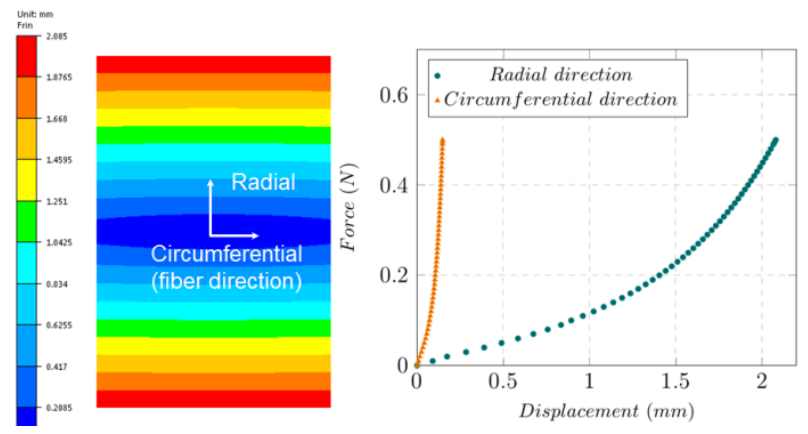

Figure 1: Finite element model of a biaxial tensile test (left: displacement field, right: resulting force $v s$. displacement curves)

Those protocols were then experimentally reproduced (Figure 2).

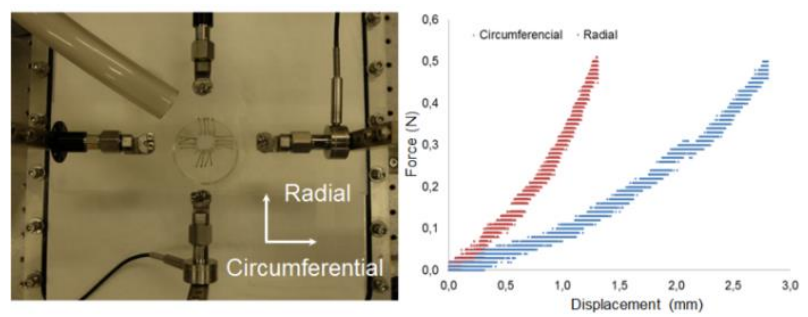

Figure 2: Planar biaxial tensile test (left) and force $v s$. displacement curve associated (right)

Inverse analysis identification based on experimental data allowed the identification of material model parameters.

\subsection{Discussion}

In this study we considered, as a first approximation, monolayer homogenous materials for the heart valve leaflets. Moreover, having no local information available at this stage in terms of collagen fiber orientation, the same preferred fiber direction was assigned everywhere in our numerical model. From the experimental point of view, the way the specimen are gripped may generate some local stress concentrations, especially in the case of small size samples and of a strong anisotropy [5]. Moreover, it is extremely difficult to determine a single preferred fiber direction [2] and thus to align it with the device axes.

\section{Conclusions}

This paper is a preliminary study. The method presented allowed us to reduce the number of biaxial tensile test commonly used for identifying the mechanical properties of AV tissues. Thanks to this sensitivity analysis, a limited number of experiments were carried out to determine a first set of material parameters. In order to improve our results, further information is still required: local strain fields are planned to be obtained using a digital image correlation system. They will allow us to fix and determine a preferred fiber orientation on each element. In situ measurements using a multiphoton microscope will allow us to determine how the fiber network evolved during stretching.

\section{Acknowledgements}

The authors thank Carnot M.I.N.E.S for support through grant 20531.

\section{References}

[1] A. Hasan, K. Ragaert, W. Swieszkowski, IvSeila Selimović, A. Paul, G. Camci-Unal, M. R. Mofrad, and A. Khademhosseini, "Biomechanical properties of native and tissue engineered heart valve constructs," Journal of biomechanics, 2013.

[2] K. L. Billiar and M. S. Sacks, "Biaxial mechanical properties of the natural and glutaraldehyde treated aortic valve cusp : Part I - Experimental results," Journal of Biomechanical Engineering, vol. 122, no. 1, pp. 23-30, 2000.

[3] J. A. Stella, J. Liao, and M. S. Sacks, "Timedependent biaxial mechanical behavior of the aortic heart valve leaflet," Journal of biomechanics, vol. 40, no. 14, pp. 3169-3177, 2007.

[4] T. C. Gasser, R. W. Ogden, and G. A. Holzapfel, "Hyperelastic modelling of arterial layers with distributed collagen fibre orientations," Journal of the royal society interface, vol. 3, no. 6, pp. 15-35, 2006.

[5] Wei Sun, Michael S. Sacks, and Michael J. Scott, "Effects of boundary conditions on the estimation of the planar biaxial mechanical properties of soft tissues," Journal of Biomechanical Engineering, vol. 127, pp. 709-715, 2005. 